\title{
Katrina scars tens of thousands psychologically
}

Published at www.cmaj.ca on Sept. 13, 2005. Revised Sept. 16, 2005.

Tens of thousands of victims of Hurricane Katrina in the US Gulf Coast states are psychologically scarred from the trauma and will need help, says a Canadian emergency physician who travelled to Louisiana as part of Vancouver's Urban Search and Rescue team.

"Many of the people that we saw had this vacant stare in their eyes," Dr. Mike Flesher, 44, told CMA7. "They were mentally and physically exhausted."

Flesher was one of 45 team members, including 8 paramedics, who flew to Louisiana from Vancouver on Aug. $31-2$ days after Katrina struck.

The Canadians were the first emergency responders to arrive at the emergency operations centre for St. Bernard Parish, a New Orleans suburb of 70000 .
The parish president hugged the team leader when they arrived. "Policemen were weeping to see us," says Flesher, head of emergency at Nanaimo Regional General Hospital in BC.

The team was escorted by Louisiana state troopers as they rescued 119 people from their homes, treated about 150 others, and brought many evacuees to safety. The team also resupplied a local medial clinic.

The most serious health conditions involved people with chronic diseases complicated by dehydration, physical exhaustion and heat exhaustion. Others had minor scrapes that were a major concern because of the contaminated water.

Flesher could not do much to treat the psychological problems

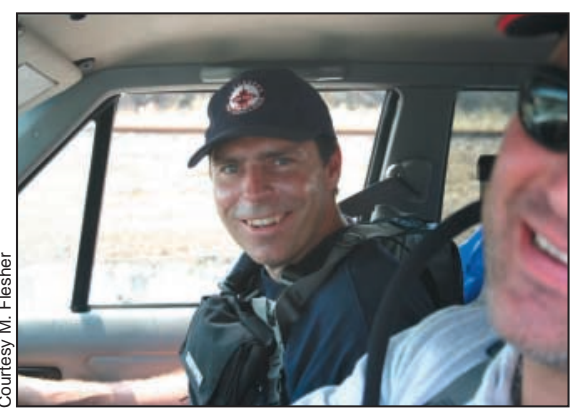

"Policemen were weeping to see us," said Dr. Mike Flesher.

he saw, except to offer reassurance and some practical help. He hopes trained Red Cross volunteers will be able to offer counselling. "There was really no time for us to spend a lot of time with the victims." The team returned to Canada Sept. 6. Laura Eggertson, CMAJ

\section{Health Human Resources}

\section{Med schools need to train more doctors: Dosanjh}

In light of the physician shortage and long wait lists, Canada's 17 medical schools must increase enrolment and provincial governments must work harder with professional bodies to license more international medical graduates, says Health Minister Ujjal Dosanjh.

Canada has 2.1 physicians per 1000 population, compared to an average of 2.8 among the other member-nations of the Organization for Economic Cooperation and Development. In 2004, there were 60612 physicians in Canada.

Part of the problem is that there are only 6.5 medical school positions per 100000 population in Canada; by comparison, the UK has 12.2 openings.

In addition to increasing enrolment, Canada must also boost the number of residency positions, Dosanjh told reporters on Aug. 29.

The CMA, which is setting up a Centre for Health Workforce Research and Planning, advocates 120 residency spots per 100 medical graduates.

Last year, the federal government set aside $\$ 75$ million over 5 years to offset the expense of training more doctors, but no province has yet accessed that money, said Dosanjh. The funds are available based on the number of additional residency spots created, not on a per capita allocation.

Meanwhile, the shortage is growing. The proportion of FPs accepting new patients declined from $23.7 \%$ in 2001 to $20.2 \%$ in 2004, states a new report from the Canadian Institute for Health Information. In 2003, $15.8 \%$ of Canadians reported difficulty in accessing routine or ongoing care.

"If the shortage gets worse, patient safety will be compromised and wait lists will increase," said former CMA Presi- dent Dr. Albert Schumacher. It is bound to get worse, given that 3800 physicians plan to retire this year.

One solution, said Dosanjh, is to lower barriers that prevent international medical graduates (IMGs) from gaining accreditation. One of those barriers is the shortage of re-entry training positions. Last year, 680 IMGs qualified for training but there were only 80 re-entry positions. The CMA General Council recommends a 4-fold increase.

IMGs are part of the shortterm solution, but the CMA emphasized the need for physician self-sufficiency. Currently, $24 \%$ of Canada's doctors are IMGs. "Wealthy Canadians cannot and must not rely on systematic recruitment of doctors from countries that cannot legitimately afford it," said former CMA President Peter Barrett. - Laura Eggertson and Barbara Sibbald, CMAJ 